\title{
Produto interno bruto, emprego e renda do macrossetor da construção civil paranaense em 2006
}

\author{
Gross domestic product, employment and income in the \\ construction macro-sector from Paraná in 2006
}

\section{Ricardo Kureski}

\section{Resumo}

ste artigo apresenta os multiplicadores de emprego e renda, direto, indireto e induzido para a economia do estado do Paraná, dando ênfase à indústria da Construção Civil. O primeiro passo para a realização do trabalho foi estimar a matriz de insumo-produto do estado do Paraná para 2006, por meio do método RAS. Na sequência, obteve-se o Produto Interno Bruto do macro-setor da Construção Civil - cerca de 8,07\% do PIB do estado. Também foram estimados os volumes de emprego e renda direto e indireto induzido. Os resultados apontaram que o consumo final da indústria da Construção Civil gera 423,5 mil empregos, no valor de 2.418 milhões de reais de renda do trabalho.

Palavras-chave: Construção Civil. Produto Interno Bruto. Emprego e renda. Matriz de insumo-produto. Paraná.

Ricardo Kureski Centro de Ciências Sociais Aplicada Pontifícia Universidade Católica do

Paraná Rua Imaculada Conceição, 1155, Prado
Velho Velho Curitiba - PR - Brasil Telefone: (41) 3271-2595 E-mail: kureski@ipardes.pr.gov.br

Recebido em 11/02/11 Aceito em 29/07/11

\section{Abstract}

This article presents the direct, indirect and inducted multipliers of employment and income in the Paraná state's economy, focusing on the Construction Industry. The first step in the study was to estimate the input-output matrix from Paraná State, in 2006, using the RAS method. Subsequently, the Gross National Product of the Construction macro sector was obtained - about 8,07\% of the state's GNP. Estimations were also made of the amount of direct, indirect and induced employment and income. The results have indicated that the final consumption of the Construction Industry creates 423,5 thousand jobs, equivalent to 2.418 million reais of work income.

Keywords: Construction Industry. Gross Domestic Product. Employment and income. Input-output matrix. Paraná. 


\section{Introdução}

A indústria da construção civil, em momentos de baixo crescimento econômico e alto desemprego, é alavancada por políticas públicas, de investimento em moradias e infraestrutura, o que diminui, principalmente, o nível de desemprego. A escolha dessa atividade econômica decorre principalmente das relações intersetoriais da construção civil e de seus fornecedores. A construção civil, também é segmento, que mesmo com o avanço tecnológico, impulsiona o mercado de trabalho.

Para o World Bank (1984), a variação da demanda da construção afeta a economia de muitas maneiras, principalmente na demanda de trabalho e insumo da construção civil. AS ligações para trás, geram impacto generalizado, porque grande parte da matéria-prima, semielaborados e acabados são fornecidas por empresas nacionais, intensiva em mão de obra. As relações intersetoriais da construção civil afetam praticamente todos os outros setores da economia. Assim, o aumento da produção da construção civil estimula um crescimento substancial da economia. Dessa forma, a construção civil é um agente de desenvolvimento econômico, por ser capaz de proporcionar emprego e renda a um grande número de trabalhadores, qualificados e não qualificados.

Quando se estuda o conjunto de atividades que fornecem insumo para a construção civil, está-se referindo ao macrossetor da Construção Civil. As contas nacionais e regionais brasileiras não mensuram o valor do produto interno bruto (PIB) desse macrossetor. Assim, na literatura acadêmica, existem alguns trabalhos que desenvolvem procedimento metodológico para mensurar o PIB do macrossetor da Construção Civil, tais como o de Oliveira e Silva (2006), Kureski et al. (2008) e da Câmara Brasileira da Indústria da Construção Civil (CBIC) e Fundação Getúlio Vargas (FGV) (2002). Para estimar o PIB do macrossetor da Construção Civil, os autores utilizam a matriz de insumo-produto, divulgada pelo Instituto Brasileiro de Geografia e Estatística (IBGE) (2008a).

A indústria da construção civil paranaense empregou em 200663.916 pessoas, o que corresponde a $5 \%$ do total de empregados na construção civil brasileira. $\mathrm{O}$ valor bruto da produção, das 2.106 empresas da construção no Paraná foi de 4.687,65 milhões de reais. Em razão da importância da indústria da construção civil para a economia, este trabalho tem o objetivo de mensurar o produto interno bruto do macrossetor da Construção Civil paranaense no ano de 2006. Também é estimado o volume de emprego e renda.

A escolha do ano de 2006 para realizar o trabalho deu-se porque a matriz de insumo-produto disponível para o estado do Paraná é desse ano. Para a elaboração da matriz empregou-se o método RAS, que produz resultados melhores, se comparado com o método Quociente Locacional Simples (utilizado na matriz de 2000), pois são necessários volumes maiores de informações da economia estadual no primeiro. Por fim, cabe ressaltar que este é o primeiro trabalho a mensurar o macrossetor da Construção Civil paranaense.

$\mathrm{O}$ artigo está dividido em quatro seções além desta parte introdutória. As metodologias para a construção da matriz de insumo-produto, do PIB do macrossetor da Construção Civil e do multiplicador de emprego e renda são apresentadas na segunda seção. Na terceira seção é apresentado o PIB do macrossetor da Construção Civil paranaense e o volume de emprego e renda gerado; e a quarta seção apresenta as principais conclusões do estudo.

\section{Metodologia}

O macrossetor da Construção Civil corresponde não somente à atividade da construção civil como também às atividades fornecedoras de insumos, transporte, comércios e outros serviços. As metodologias desenvolvidas para mensurar o PIB dos macrossetores e o emprego e renda direto, indireto e induzido utilizam a matriz de insumoproduto. Entretanto, no estado do Paraná, não existia uma matriz compatível com as contas regionais. Assim, o primeiro passo para a realização deste trabalho foi elaborar a matriz paranaense, cuja metodologia é apresentada a seguir.

\section{Matriz de insumo-produto}

A matriz de insumo-produto é elaborada a partir de sua divisão em três setores, obtendo-se para cada setor o consumo intermediário, a demanda final e o valor bruto da produção. Com a dedução do valor bruto da produção do consumo intermediário obtém-se o valor adicionado, conforme demonstra o Quadro 1. 


\begin{tabular}{|c|c|c|c|c|c|}
\hline \multirow{2}{*}{ De } & \multicolumn{3}{|c|}{ Para } & \multirow{2}{*}{ Demanda final } & \multirow{2}{*}{ Valor bruto da produção } \\
\cline { 2 - 5 } & $\mathbf{1}$ & $\mathbf{2}$ & $\mathbf{3}$ & & $\mathrm{X}_{1}$ \\
\hline $\mathbf{1}$ & $\mathrm{X}_{11}$ & $\mathrm{X}_{12}$ & $\mathrm{X}_{13}$ & $\mathrm{Y}_{1}$ & $\mathrm{X}_{2}$ \\
\hline $\mathbf{2}$ & $\mathrm{X}_{21}$ & $\mathrm{X}_{12}$ & $\mathrm{X}_{23}$ & $\mathrm{Y}_{2}$ & $\mathrm{X}_{3}$ \\
\hline $\mathbf{3}$ & $\mathrm{X}_{31}$ & $\mathrm{X}_{32}$ & $\mathrm{X}_{33}$ & $\mathrm{Y}_{3}$ & $\mathrm{~V}$ \\
\hline Valor adicionado & $\mathrm{V}_{1}$ & $\mathrm{~V}_{2}$ & $\mathrm{~V}_{3}$ & - & $\mathrm{X}$ \\
\hline Valor bruto da produção & $\mathrm{X}_{1}$ & $\mathrm{X}_{2}$ & $\mathrm{X}_{3}$ & $\mathrm{Y}$ & $\mathrm{Y}$ \\
\hline
\end{tabular}

Quadro 1 - Matriz de insumo-produto

Fonte: Richardson (1978, p. 35).

O coeficiente técnico é definido como a necessidade direta de insumos dos diversos setores de atividades, portanto demonstra as relações intra e interindustriais diretas. Miernyk (1974) conceitua o coeficiente técnico como sendo o montante de insumo requerido de cada indústria a fim de elaborar um produto, no valor $\$ 1$, que pode ser obtido pela Equação 1:

$\mathrm{a}_{\mathrm{ij}}=\mathrm{X}_{\mathrm{ij}} / \mathrm{X}_{\mathrm{j}}$

Eq. 1

Onde:

aij = coeficiente técnico;

$\mathrm{Xij}=$ consumo intermediário; $\mathrm{e}$

$\mathrm{Xj}=$ valor da produção da indústria.

O aumento da demanda final ocasiona, além dos efeitos diretos na produção de insumos, efeitos indiretos, ou seja, ocorre a primeira rodada de compras, a segunda rodada, a terceira rodada, e assim por diante. A fim de determinar os efeitos diretos e indiretos, faz-se necessário utilizar a matriz inversa de Leontief, através da Equação 2:

$\mathrm{X}=[\mathrm{I}-\mathrm{A}]^{-1}$.Y

Eq. 2

Onde:

$\mathrm{X}=$ matriz do valor bruto da produção;

$\mathrm{I}=$ matriz identidade;

$\mathrm{A}=$ matriz dos coeficientes técnicos; e

$\mathrm{Y}=$ matriz dos valores da demanda final.

\section{Metodologia da Matriz de insumo-produto paranaense}

A metodologia utilizada difere das metodologias empregadas anteriormente para a estimativa da matriz de insumo-produto paranaense, as quais empregam o método do Quociente Locacional Simples, que tem como princípio a transformação dos coeficientes nacionais em regionais (KURESKI; CABALLERO, 2005).

A nova metodologia baseia-se no trabalho da matriz, de 2003, do Rio Grande do Sul (FUNDAÇÃO..., 2007), adaptada à base de dados da economia paranaense, que consiste na elaboração da Tabela de Recursos e Usos estadual e na utilização do método de ajuste biproporcional denominado RAS. Essa metodologia produz resultados melhores, se comparado com método do Quociente Locacional Simples, pois são necessários volumes maiores de informações da economia estadual. Entretanto, o custo e o tempo de elaboração da matriz para o método RAS superam os do método do Quociente Locacional Simples.

Os dados do valor bruto da produção e o consumo intermediário para as atividades econômicas paranaenses foram obtidos nas contas regionais do Brasil. Entretanto, foi necessário desagregar os valores da indústria. Nesse caso, utilizou-se a Pesquisa Industrial Anual de 2006, publicada pelo IBGE (2008b).

$\mathrm{O}$ valor das exportações e importações para o resto do mundo no exterior tem como fonte a Secretaria de Comércio Exterior (Secex), do Ministério do Desenvolvimento, Indústria e Comércio do Brasil (2009). Os dados foram classificados conforme Classificação Nacional das Atividades Econômicas, CNAE 1.0 (IBGE, 2003), e agregados em 88 produtos da Tabela de Recursos e Usos. Para as exportações e importações interestaduais, utilizaram-se os dados de entradas e saídas da Secretaria da Fazenda do Estado do Paraná. Quanto à distribuição das importações da agropecuária, indústria e serviços entre produtos, utilizou-se a estrutura do consumo intermediário da Tabela de Recursos de Bens e Serviços brasileira de 2006. Segundo FEE (2007, p. 13), esse tratamento especial é necessário, no que se refere aos dados de importações interestaduais, porque as informações da Secretaria da Fazenda (SEFAZ) são classificadas de acordo com a principal atividades produtoras. Assim, os valores das entradas representam as importações de vários segmentos da economia. Como exemplo, podemos citar a indústria automobilística, que importa produtos do segmento de autopeças, borracha e tinta. Para a atividade do comércio não se realizou nenhuma modificação dos dados. 
Nas contas nacionais do Brasil não são especificadas as margens de comércio e transporte para os estados. Em razão da dificuldade para se conseguirem esses dados em âmbito regional, utilizou-se a estrutura da margem de comércio e transporte para o Brasil de 2006, para se obterem as primeiras estimativas para as margens. Quando do equilíbrio, procedeu-se a novos ajustes nas margens.

Para se obter o valor do imposto sobre a produção industrial, foram utilizados os dados de arrecadação da Receita Federal. Quanto à indústria de fumo, bebidas e automóveis, obteve-se o valor do imposto aberto. Para os demais produtos, utilizou-se a mesma alíquota da Tabela de Recursos e Usos de 2006 para a economia brasileira. No caso do ICMS, os valores correspondem ao valor divulgado pela Secretaria da Fazenda do Paraná. Os procedimentos metodológicos descritos para margens e impostos seguem os procedimentos utilizados para a construção da Tabela de Recursos de Bens e Serviços de 2003, do Rio Grande do Sul (FUNDAÇÃO..., 2007), com poucas alterações.

O consumo das famílias resultou da estrutura da Pesquisa de Orçamento Familiar do Instituto Brasileiro de Geografia e Estatística. Finalizando, a formação bruta de capital fixo e a variação dos estoques foram estimadas a partir da participação do valor da produção a preço básico do Paraná no valor da produção a preço básico do Brasil. A proporção encontrada foi multiplicada pela formação bruta de capital e estoque da Tabela de Recursos e Usos do Brasil de 2006. O resultado foi uma primeira estimativa regional da formação bruta de capital fixo e variação dos estoques.

Por meio dos procedimentos metodológicos apresentados acima, obteve-se a primeira aproximação das tabelas de recursos de bens e serviços e de usos de bens e serviços a preço de consumidor para o estado do Paraná, de 2006. Como as informações são de fontes diversas, o total da oferta de bens e serviços difere do total da demanda de bens e serviços. As equações 3 e 4 representam o equilíbrio:

Oferta $=\mathrm{P}+\mathrm{Mrm}+$ Moest. $+\mathrm{MC}+\mathrm{MT}+\mathrm{IPI} / \mathrm{ISS}$

$+\mathrm{ICMS}+$ OIMS

Eq. 3

Onde:

$\mathrm{P}=$ Produção;

Mrm = Importação do resto do mundo;

Moest $=$ Importação de outros estados;

$\mathrm{MC}=$ Margem de comércio;

MT = Margem de transporte;
IPI/ISS = Imposto sobre Produtos Industrializados e Imposto sobre Serviços; e

OILS $=$ Outros impostos, menos subsídios.

Demanda $=\mathrm{CI}+$ Xrm + Xoest $+\mathrm{G}+\mathrm{ISFLSF}+\mathrm{CF}$

$+\mathrm{FBKF}+\Delta \mathrm{E}$

Eq. 4

Onde:

$\mathrm{CI}=$ Consumo intermediário;

$\mathrm{Xrm}=$ Exportações para o resto do mundo;

Xoest $=$ Exportação para os outros estados;

$\mathrm{G}=$ Consumo da administração pública;

ISFLSF $=$ Consumo das ISFLSF;

$\mathrm{CF}=$ Consumo das famílias;

FBKF = Formação bruta de capital fixo; e

$\Delta \mathrm{E}=$ Variação de estoques.

Assim, o equilíbrio pode ser apresentado como:

$$
\text { Oferta }=\text { Demanda }
$$

Os resultados do PIB do estado do Paraná divulgados pelo IBGE não se alteram quando do equilíbrio da matriz. Isso porque os valores da produção paranaense e do consumo intermediário não poderiam diferir dos divulgados nas contas regionais. Também se estabeleceu que os valores das exportações e importações para o resto do mundo não seriam alterados. $\mathrm{O}$ equilíbrio foi realizado em 88 planilhas, levando-se em conta o produto. Na Tabela 1 é apresentado o modelo de tabela de equilíbrio. Nela, pode-se constatar que a produção farmacêutica estadual não é suficiente para atender à demanda, sendo necessárias as importações de outros estados. A Oferta a preço de mercado totalizou 4.717 milhões de reais, tendo como principal destino o consumo das famílias e o consumo intermediário.

Quando da elaboração do equilíbrio, somente se obtém o valor do consumo intermediário fechado. Para estimar os coeficientes técnicos da matriz, utilizou-se o método RAS. Miller (1998) compara os resultados obtidos para a matriz de insumo-produto de Washington obtidos pelos métodos do Quociente de Localização do RAS. ${ }^{1}$ Conclui o autor que o método do RAS obteve melhor resultado em razão da necessidade de uma maior quantidade de dados.

A Tabela de Recursos e Usos é resultante do processo de equilíbrio foi obtida a preço de mercado. Para se elaborar a matriz inversa de Leontief, é necessária a Tabela de Recursos e Usos a preço básico. Em outras palavras, devem-se

${ }^{1}$ Para melhor entendimento do método RAS, ver Miller (1998, p. 89). 
excluir do consumo intermediário e da demanda final os valores das margens de comércio e transporte e do total de impostos líquidos de subsídios. Assim, para obter a tabela de recursos e usos a preço básico, adotou-se o procedimento metodológico apresentado por Guilhoto et al. (2002).

\section{Metodologia do PIB do macrossetor da Construção Civil}

A metodologia empregada para o cálculo do PIB dos agronegócios brasileiro e gaúcho foi apresentada por Guilhoto, Furtuoso e Barros (2000) e Finamore e Montoya (2003). Para o PIB do macrossetor da Construção Civil brasileira em 2004, empregou-se a metodologia demonstrada por Kureski (2008).

Para calcular o valor adicionado resultante das vendas para a construção civil, primeiramente é necessário levantar o coeficiente do valor adicionado (Equação 5). Isso se faz para evitar o erro de múltipla contagem, pois o valor fornecido não corresponde ao valor adicionado, mas sim a uma parte do valor da produção, que é fornecido à atividade pelos demais setores.
Logo:

$\mathrm{CVA}_{\mathrm{i}}=\mathrm{VA}_{\text {pmi }} / \mathrm{X}_{\mathrm{i}}$

Eq. 5

Em que:

$\mathrm{CVA}_{\mathrm{i}}=$ coeficiente de valor adicionado;

$\mathrm{VA}_{\mathrm{pmi}}=$ valor adicionado; $\mathrm{e}$

$\mathrm{X}_{\mathrm{i}}=$ valor da produção.

Multiplicando-se o coeficiente do valor adicionado pelo valor do fornecimento de insumos, conforme a Equação 6, obtém-se o PIB referente ao fornecimento de insumos à construção civil. Tem-se então:

$P I B_{\mid}=\sum_{i=j}^{n} Z_{i} * C V A_{i}$

Eq. 6

Em que:

$\mathrm{PIB}_{\mathrm{ik}}=\mathrm{PIB}$ do agregado I (insumos) da atividade construção civil;

$\mathrm{Z}_{\mathrm{i}}=$ valor total do insumo de setor i para a atividade construção civil; e

$\mathrm{CVA}_{\mathrm{i}}=$ coeficiente de valor adicionado do setor $\mathrm{i}$.

Tabela 1 - Planilha de equilíbrio do produto farmacêutico

\begin{tabular}{|c|c|c|c|c|c|c|c|c|}
\hline \multirow[b]{2}{*}{ Composição do preço } & \multirow[b]{2}{*}{$\begin{array}{l}\text { Preço } \\
\text { básico }\end{array}$} & \multicolumn{6}{|c|}{ Produto: Produtos farmacêuticos } & \multirow[b]{2}{*}{ Total preço de mercado } \\
\hline & & MC & MT & \multicolumn{4}{|c|}{ Impostos } & \\
\hline & & & & & & & & \\
\hline Produção & $443 *$ & & & & & & & \\
\hline Importação do resto do mundo & 193 & & & & & & & \\
\hline Importação de outros estados & 2.415 & & & & & & & \\
\hline Total dos recursos & 3.052 & 1.232 & 29 & 6 & 2 & 362 & 36 & 4.717 \\
\hline Demanda (ou uso) & & & & & & & & \\
\hline Consumo intermediário & & & & & & & & 1.924 \\
\hline Exportações p/ resto do mundo & & & & & & & & 9 \\
\hline Exportação p/ outros estados & & & & & & & & 369 \\
\hline Consumo da administração pública & & & & & & & & 0 \\
\hline Consumo das ISFLSF & & & & & & & & 0 \\
\hline Consumo das famílias & & & & & & & & 2.416 \\
\hline Formação bruta de capital fixo & & & & & & & & 0 \\
\hline Variação de estoques & & & & & & & & 0 \\
\hline Total dos usos & & & & & & & & 4.717 \\
\hline Saldo & & & & & & & & 0 \\
\hline
\end{tabular}

Nota: valores correntes em milhões de reais. 
O fornecimento de insumos para o próprio setor não foi calculado pela Equação 4. Assim, no valor do PIB da atividade construção civil está incorporada a parcela do PIB das vendas de insumo dentro da própria atividade. Esse procedimento evita a necessidade de se descontar do PIB da construção civil a parcela referente ao PIB do agregado I (insumos). Guilhoto, Furtuoso e Barros (2000) adotaram o procedimento de descontar do valor adicionado da agricultura e pecuária a parcela do valor adicionado correspondente de insumos, para evitar a dupla contagem. Esse procedimento não será adotado neste trabalho, já que não se calculará o PIB referente à compra de insumos dentro da própria atividade. Dessa forma, o PIB da atividade construção civil é resultado da seguinte Equação 7:

$\mathrm{PIB}_{\mathrm{ll}}=\mathrm{VBP}_{\mathrm{j}}-\mathrm{CI}_{\mathrm{j}}$

Eq. 7

Em que:

$\mathrm{PIB}_{\mathrm{II}}=\mathrm{PIB}$ do agregado II para a atividade construção civil;

$\mathrm{VBP}_{\mathrm{j}}=$ valor da produção a preço básico da construção civil; e

$\mathrm{CI}_{\mathrm{j}}=$ consumo intermediário da atividade construção civil.

Esse procedimento de cálculo é o adotado pelo IBGE para determinar o PIB das atividades econômicas. Para concluir o cálculo, é necessário obter o valor do PIB gerado pela distribuição final da construção civil, que corresponde à margem de comércio e transporte. O PIB referente à demanda final é uma parcela correspondente à participação da atividade construção civil no total da demanda final, a qual é obtida por meio da Equação 8:

$\mathrm{PIB}_{\mathrm{III}}=(\mathrm{VAC}+\mathrm{VAT}+\mathrm{VAS}) *\left(\sum \mathrm{DF}_{\mathrm{i}} / \mathrm{DF}\right) \quad$ Eq. 8

Onde:

$\mathrm{PIB}_{\mathrm{III}}=\mathrm{PIB}$ do agregado III (demanda final) atividade construção civil;

$\mathrm{VAC}=$ valor adicionado dos comércio;

$\mathrm{VAT}=$ valor adicionado dos transporte;

VAS = valor adicionado dos serviços;

$\mathrm{DFi}=$ demanda final para a atividade construção civil a preço básico; e

$\mathrm{DF}=$ demanda final a preço básico.

O PIB do macrossetor da Construção Civil corresponde à soma dos PIBs dos agregados, conforme a Equação 9:

PIB Macrossetor da Construção civil $=$ PIB $_{I+}$ $\mathrm{PIB}_{\mathrm{II}}+\mathrm{PIB}_{\mathrm{III}}$ Eq. 9

\section{Multiplicador de emprego e renda}

O multiplicador de emprego tem o objetivo de demonstrar para a atividade $\mathrm{j}$ o volume de emprego direto, indireto e induzido resultante do aumento de uma unidade monetária na demanda final.

Quando do aumento da demanda final, ocorre um incremento do consumo intermediário repercutindo no crescimento da produção das demais atividades. Esse incremento da produção denomina-se primeira rodada. Porém, a atividade fornecedora de insumo também comprará mais insumo para atender ao incremento de sua produção. Tem-se, então, a segunda rodada.

O número de rodadas na economia é infinito. Cada novo acréscimo na compra de insumos gera empregos indiretos. Para medir o emprego indireto, é necessário calcular o emprego total (Equação 10), utilizando a matriz de Leontief aberta. Assim, tem-se:

$E_{j}=\sum_{i=1}^{n}\left(w_{n+1, i} 1_{i j}\right)$

Em que:

$w_{\mathrm{n}+1}$ é o coeficiente de emprego do setor; e

lij é o elemento da matriz inversa de Leontief aberta.

O emprego indireto é a diferença entre o emprego total e o emprego direto. O incremento no aumento da produção também resulta no aumento do emprego decorrente do aumento da renda, ou seja, o "efeito renda". As pessoas que ocupam os novos postos de trabalho recebem salários, os quais utilizam na compra de produtos para a satisfação de suas necessidades, gerando um novo acréscimo na demanda final e de novos empregos. Para mensurar o efeito renda, é necessário endogenizar a variável consumo das famílias. O emprego total no modelo fechado é expresso da seguinte forma:

$\overline{\mathrm{E}}_{\mathrm{j}}=\sum_{\mathrm{i}=1}^{\mathrm{n}}\left(\mathrm{w}_{\mathrm{n}+1, \mathrm{i}} \overline{\mathrm{b}}_{\mathrm{ij}}\right)$

Eq. 11

O emprego induzido é resultado da diferença entre o emprego total do modelo fechado (Equação 11) e o emprego total para o modelo aberto (Equação 10). Finalizando, a soma dos empregos direto, indireto e induzido resulta no emprego total.

O multiplicador de renda demonstra para a atividade $\mathrm{j}$ o volume de renda resultante do aumento de uma unidade monetária na demanda final. O multiplicador de renda total (Equação 12), para matriz de Leontief aberta, é dado por: 
$\mathrm{W}_{\mathrm{j}}=\sum_{\mathrm{i}=1}^{\mathrm{n}}\left(\mathrm{w}_{\mathrm{n}+1, \mathrm{i}} \mathbf{1}_{\mathrm{ij}}\right)$

Eq. 12

Em que:

$w_{n+1}$ é o coeficiente de renda do setor; e

$1_{i j}$ é o elemento da matriz inversa de Leontief aberta.

$\mathrm{O}$ incremento na demanda final faz com que as empresas aumentem a produção, gerando novos empregos e salários. As famílias utilizam a renda para o consumo de bens e serviços finais. As empresas, para atender a essa nova demanda, contratam novos empregados, o que implica mais salários. Assim, temos o chamado efeito renda. Para se obter o efeito renda é necessário calcular a renda total gerada utilizando-se a matriz de Leontief fechada. O multiplicador de renda é apresentado pela Equação 13:

$$
\overline{\mathbf{W}}_{\mathrm{j}}=\sum_{\mathrm{i}=1}^{\mathrm{n}}\left(\mathrm{w}_{\mathrm{n}+1, \mathrm{i}} \overline{\mathrm{b}}_{\mathrm{ij}}\right)
$$

A renda induzida é resultado da diferença entre a renda total do modelo fechado (Equação 13) e o emprego total para o modelo aberto (Equação 12). A renda total pode ser obtida diretamente na Equação 13, que incorpora os efeitos direto, indireto e induzido.

\section{Resultados e Discussão}

A Figura 1 exibe o PIB do macrossetor da Construção Civil paranaense em 2006. O valor do PIB difere dos realizados pela metodologia tradicional, pois considera também o fluxo de compra e venda dos setores e a margem de comercialização, ou seja, é mensurado também o PIB das relações intersetoriais.

$\mathrm{O}$ PIB dos insumos, referente à compra de bens e serviços intermediários, representa $1,37 \%$ do PIB paranaense. As principais atividades fornecedoras de insumos são: outros produtos de minerais não metálicos, cimento, artigos de borracha e plástico, tintas, vernizes, esmaltes e lacas, produtos de metal - exclusive máquinas e equipamentos - e produtos de madeira - exclusive móveis. O resultado para a indústria da construção civil indica em 4,09\% a participação dessa atividade no total da economia paranaense. Assim, a participação da construção na formação bruta de capital ficou em 37,50\%, resultado abaixo daquele encontrado para a economia brasileira, 40,21\%, em 2006. O resultado desfavorável para a indústria de construção paranaense reflete o crescimento real acumulado do PIB da construção entre 2002 e 2006, de $-0,54 \%$. Lourenço $(2007$, p. 2 ), ao explicar o fraco desempenho da indústria da madeira e minerais não metálicos em 2006, deve-se mais que decenal instabilidade da construção civil, particularmente a atividades pesadas vinculadas aos investimentos em infraestrutura. No que se refere à contribuição, comércio, transporte e serviço no PIB, o resultado foi de $2,6 \%$.

O total da contribuição para a economia paranaense do macrossetor da Construção Civil foi de 9,65 bilhões de reais, o que corresponde a uma participação na economia de $8,07 \%$. Ao se analisar a composição do macrossetor, conclui-se que os insumos, a construção civil e o comércio, transporte e serviço respondem por $17,0 \%, 50,7 \%$ e $32,3 \%$ do PIB do macrossetor respectivamente.

Com a utilização dos dados de emprego da matriz de insumo-produto paranaense, foram estimados os multiplicadores de empregos direto, indireto e induzido para um aumento de $\mathrm{R} \$ 1$ milhão na demanda final. A atividade Outros Serviços (52) destaca-se em primeiro lugar, com 169 empregos, computando o aumento de 1 milhão de reais em sua demanda final (Tabela 2). Entre as atividades que compõem o volume de emprego total estão os serviços de lavanderias, tinturarias, cabeleireiros, tratamentos de beleza, entidades recreativas, culturais e desportivas e os empregos domésticos. Esses serviços são intensivos em mão de obra, resultando em multiplicador de emprego acima das demais atividades.

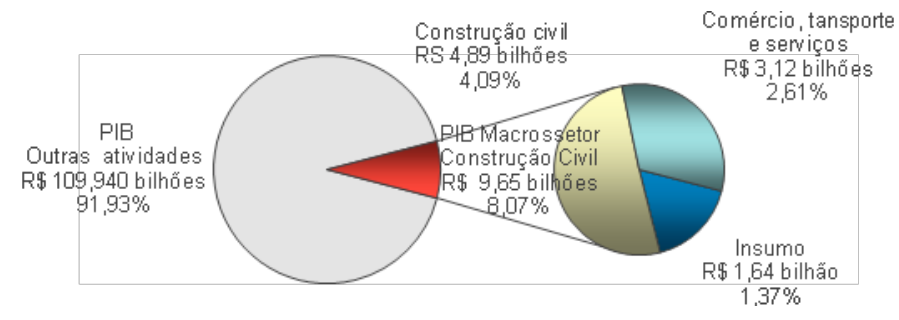

Figura 1 - Produto Interno Bruto do macrossetor da construção civil paranaense em 2006

Nota: Produto Interno Bruto a preço básico, Gráfico baseado no trabalho de Guilhoto, Ichihara e Postali (2006). 
Tabela 2 - Multiplicadores de emprego direto, indireto e induzido pela variação da demanda final de um milhão de reais no Paraná em 2006

\begin{tabular}{|c|c|c|c|c|}
\hline \multirow{2}{*}{ ATIVIDADE } & \multicolumn{4}{|c|}{ MULTIPLICADORES } \\
\hline & Direto & Indireto & Induzido & TOTAL \\
\hline 1 Agricultura, silvicultura, exploração florestal & 53 & 7 & 10 & 70 \\
\hline 2 Pecuária e pesca & 48 & 13 & 12 & 73 \\
\hline 3 Extrativa mineral & 9 & 9 & 8 & 26 \\
\hline 4 Alimentos e bebidas & 6 & 24 & 10 & 39 \\
\hline 5 Produtos do fumo & 2 & 3 & 10 & 14 \\
\hline 6 Têxteis & 24 & 8 & 8 & 39 \\
\hline 7 Artigos do vestuário e acessórios & 73 & 7 & 12 & 92 \\
\hline 8 Artefatos de couro e calçados & 15 & 10 & 15 & 40 \\
\hline 9 Produtos de madeira - exclusive móveis & 11 & 15 & 10 & 36 \\
\hline 10 Celulose e produtos de papel & 3 & 10 & 11 & 24 \\
\hline 11 Jornais, revistas, discos & 20 & 7 & 12 & 39 \\
\hline 12 Refino de petróleo e coque & 0 & 6 & 5 & 11 \\
\hline 13 Álcool & 6 & 23 & 7 & 36 \\
\hline 14 Produtos químicos & 2 & 6 & 7 & 14 \\
\hline 15 Fabricação de resina e elastômeros & 1 & 4 & 5 & 10 \\
\hline 16 Produtos farmacêuticos & 11 & 10 & 9 & 30 \\
\hline 17 Defensivos agrícolas & 2 & 8 & 8 & 18 \\
\hline 18 Perfumaria, higiene e limpeza & 9 & 13 & 8 & 30 \\
\hline 19 Tintas, vernizes, esmaltes e lacas & 5 & 7 & 9 & 21 \\
\hline 20 Produtos e preparados químicos diversos & 10 & 7 & 9 & 26 \\
\hline 21 Artigos de borracha e plástico & 11 & 5 & 10 & 26 \\
\hline 22 Cimento & 1 & 5 & 9 & 15 \\
\hline 23 Outros produtos de minerais não metálicos & 24 & 6 & 12 & 42 \\
\hline 24 Fabricação de aço e derivados & 4 & 9 & 8 & 20 \\
\hline 25 Metalurgia de metais não ferrosos & 65 & 6 & 8 & 79 \\
\hline $\begin{array}{l}26 \text { Produtos de metal - exclusive máquinas e } \\
\text { equipamentos }\end{array}$ & 9 & 5 & 9 & 24 \\
\hline $\begin{array}{l}27 \text { Máquinas e equipamentos, inclusive manutenção e } \\
\text { reparos }\end{array}$ & 5 & 6 & 11 & 22 \\
\hline 28 Eletrodomésticos & 3 & 7 & 8 & 17 \\
\hline $\begin{array}{l}29 \text { Máquinas para escritório e equipamentos de } \\
\text { informática }\end{array}$ & 4 & 7 & 6 & 17 \\
\hline 30 Máquinas, aparelhos e materiais elétricos & 8 & 6 & 9 & 23 \\
\hline 31 Material eletrônico e equipamentos de comunicações & 10 & 6 & 14 & 30 \\
\hline $\begin{array}{l}32 \text { Aparelhos/instrumentos médico-hospitalar, medida e } \\
\text { óptico }\end{array}$ & 10 & 5 & 8 & 23 \\
\hline 33 Automóveis, camionetas e utilitários & 1 & 6 & 8 & 15 \\
\hline 34 Caminhões e ônibus & 1 & 6 & 7 & 13 \\
\hline 35 Peças e acessórios para veículos automotores & 3 & 4 & 9 & 16 \\
\hline 36 Outros equipamentos de transporte & 34 & 6 & 15 & 56 \\
\hline 37 Móveis e produtos das indústrias diversas & 28 & 8 & 9 & 45 \\
\hline 38 Eletricidade e gás, água, esgoto e limpeza urbana & 3 & 3 & 8 & 14 \\
\hline 39 Construção & 37 & 5 & 9 & 52 \\
\hline 40 Comércio e Serviços de manutenção e reparação & 43 & 5 & 16 & 63 \\
\hline 41 Transporte, armazenagem e correio & 19 & 7 & 12 & 38 \\
\hline 42 Serviços de informação & 16 & 9 & 10 & 36 \\
\hline 43 Intermediação financeira e seguro & 6 & 7 & 14 & 26 \\
\hline 44 Serviços imobiliários e aluguel & 3 & 1 & 2 & 6 \\
\hline 45 Serviços de alojamento e alimentação & 41 & 8 & 10 & 59 \\
\hline 46 Serviços prestados às empresas & 37 & 7 & 16 & 60 \\
\hline 47 Educação e saúde mercantil & 33 & 8 & 19 & 60 \\
\hline 48 Outros serviços & 94 & 8 & 22 & 123 \\
\hline 49 Administração Pública & 24 & 7 & 27 & 58 \\
\hline
\end{tabular}

138 Kureski, R. 
Tabela 3 - Multiplicadores de renda direta, indireta e induzida pela variação da demanda final de um milhão de reais no Paraná em 2006

\begin{tabular}{|c|c|c|c|c|}
\hline \multirow{2}{*}{ ATIVIDADE } & \multicolumn{4}{|c|}{ MULTIPLICADORES } \\
\hline & Direto & Indireto & Induzido & TOTAL \\
\hline 1 Agricultura, silvicultura, exploração florestal & 181.162 & 54.085 & 84.203 & 319.450 \\
\hline 2 Pecuária e pesca & 206.976 & 82.782 & 103.715 & 393.473 \\
\hline 3 Extrativa mineral & 87.110 & 101.066 & 67.355 & 255.531 \\
\hline 4 Alimentos e bebidas & 102.698 & 136.504 & 85.619 & 324.820 \\
\hline 5 Produtos do fumo & 215.403 & 24.956 & 86.033 & 326.392 \\
\hline 6 Têxteis & 122.450 & 68.822 & 68.463 & 259.735 \\
\hline 7 Artigos do vestuário e acessórios & 219.689 & 53.417 & 97.754 & 370.861 \\
\hline 8 Artefatos de couro e calçados & 224.092 & 123.008 & 124.239 & 471.340 \\
\hline 9 Produtos de madeira - exclusive móveis & 136.656 & 111.186 & 88.711 & 336.554 \\
\hline 10 Celulose e produtos de papel & 168.661 & 88.058 & 91.889 & 348.607 \\
\hline 11 Jornais, revistas, discos & 193.620 & 84.030 & 99.381 & 377.031 \\
\hline 12 Refino de petróleo e coque & 56.942 & 62.610 & 42.792 & 162.344 \\
\hline 13 Álcool & 66.040 & 105.466 & 61.388 & 232.894 \\
\hline 14 Produtos químicos & 67.586 & 90.063 & 56.428 & 214.078 \\
\hline 15 Fabricação de resina e elastômeros & 36.126 & 72.441 & 38.860 & 147.426 \\
\hline 16 Produtos farmacêuticos & 110.772 & 99.855 & 75.391 & 286.018 \\
\hline 17 Defensivos agrícolas & 98.758 & 100.648 & 71.374 & 270.780 \\
\hline 18 Perfumaria, higiene e limpeza & 81.573 & 112.189 & 69.354 & 263.116 \\
\hline 19 Tintas, vernizes, esmaltes e lacas & 124.190 & 83.589 & 74.371 & 282.150 \\
\hline 20 Produtos e preparados químicos diversos & 134.996 & 78.011 & 76.243 & 289.250 \\
\hline 21 Artigos de borracha e plástico & 177.055 & 57.902 & 84.100 & 319.057 \\
\hline 22 Cimento & 160.931 & 56.115 & 77.688 & 294.733 \\
\hline 23 Outros produtos de minerais não metálicos & 206.302 & 78.789 & 102.044 & 387.135 \\
\hline 24 Fabricação de aço e derivados & 85.056 & 95.292 & 64.553 & 244.901 \\
\hline 25 Metalurgia de metais não ferrosos & 117.451 & 75.999 & 69.242 & 262.692 \\
\hline $\begin{array}{l}26 \text { Produtos de metal - exclusive máquinas e } \\
\text { equipamentos }\end{array}$ & 147.394 & 71.055 & 78.191 & 296.640 \\
\hline $\begin{array}{l}27 \text { Máquinas e equipamentos, inclusive manutenção e } \\
\text { reparos }\end{array}$ & 184.798 & 78.711 & 94.319 & 357.828 \\
\hline 28 Eletrodomésticos & 85.289 & 93.960 & 64.160 & 243.408 \\
\hline $\begin{array}{l}29 \text { Máquinas para escritório e equipamentos de } \\
\text { informática }\end{array}$ & 73.732 & 73.277 & 52.620 & 199.629 \\
\hline 30 Máquinas, aparelhos e materiais elétricos & 136.213 & 72.127 & 74.572 & 282.912 \\
\hline 31 Material eletrônico e equipamentos de comunicações & 271.219 & 71.525 & 122.680 & 465.423 \\
\hline $\begin{array}{l}32 \text { Aparelhos/instrumentos médico-hospitalar, medida e } \\
\text { óptico }\end{array}$ & 135.874 & 61.288 & 70.571 & 267.734 \\
\hline 33 Automóveis, camionetas e utilitários & 127.939 & 70.883 & 71.165 & 269.987 \\
\hline 34 Caminhões e ônibus & 80.821 & 74.925 & 55.747 & 211.492 \\
\hline 35 Peças e acessórios para veículos automotores & 156.674 & 55.454 & 75.928 & 288.055 \\
\hline 36 Outros equipamentos de transporte & 299.268 & 67.184 & 131.166 & 497.618 \\
\hline 37 Móveis e produtos das indústrias diversas & 120.785 & 80.928 & 72.200 & 273.913 \\
\hline 38 Eletricidade e gás, água, esgoto e limpeza urbana & 136.760 & 52.098 & 67.599 & 256.457 \\
\hline 39 Construção & 161.735 & 55.949 & 77.917 & 295.600 \\
\hline 40 Comércio e Serviços de manutenção e reparação & 325.799 & 46.239 & 133.166 & 505.204 \\
\hline 41 Transporte, armazenagem e correio & 214.338 & 75.429 & 103.718 & 393.485 \\
\hline 42 Serviços de informação & 158.040 & 88.747 & 88.334 & 335.122 \\
\hline 43 Intermediação financeira e seguro & 252.229 & 84.167 & 120.408 & 456.804 \\
\hline 44 Serviços imobiliários e aluguel & 28.762 & 10.322 & 13.989 & 53.073 \\
\hline 45 Serviços de alojamento e alimentação & 181.367 & 65.321 & 88.298 & 334.986 \\
\hline 46 Serviços prestados às empresas & 314.988 & 69.312 & 137.555 & 521.855 \\
\hline 47 Educação e saúde mercantil & 377.310 & 70.809 & 160.398 & 608.517 \\
\hline 48 Outros serviços & 445.379 & 65.082 & 182.712 & 693.173 \\
\hline 49 Administração Pública & 571.648 & 68.053 & 228.972 & 868.673 \\
\hline
\end{tabular}

Fonte: Cálculo do autor. 
O segundo lugar ficou com a atividade Artigos do Vestuário (7), com um coeficiente técnico de 92 empregos para o aumento de R\$ 1 milhão em sua demanda final. Como é característica dessa atividade possuir uma participação no número de empregados por conta própria, como costureiras que trabalham na própria residência, também as empresas, em sua maioria, são intensivas em mão de obra, resultando em multiplicador de emprego acima das demais atividades.

A Construção Civil (39) está classificada na décima segunda posição entre as 49 atividades. $\mathrm{O}$ aumento da demanda final nas obras da construção civil gera 37 empregos diretos, 5 indiretos e 9 em razão do efeito renda, totalizando 52 empregos. Essas atividades, que têm como característica principal o uso intensivo de mão de obra, englobam a construção de obras de infraestrutura pública e privada e a construção de moradias.

A Tabela 3 mostra os multiplicadores de renda para o aumento da demanda final de R\$ 1 milhão. Esse multiplicador considera apenas os ganhos referentes às remunerações do fator trabalho, não sendo incluída a parte do lucro. Como o valor adicionado é dividido em salários e lucro, as atividades que tiverem maior proporção do valor adicionado na conta-salário possuem um multiplicador mais elevado.

Esse caso se refere em especial às atividades relacionas à atividade terciária. Assim, a atividade Administração Pública (49), ante a característica da atividade - não visar lucro -, possui o maior multiplicador, R\$ 868.673 mil para um aumento de R\$ 1 milhão da demanda final, sendo que R\$ 571.684 mil referem-se ao efeito direto, $\mathrm{R} \$ 68.053$ mil são do efeito indireto e R\$ $228.972 \mathrm{mil}$ constituem o efeito renda.

A atividade Outros Serviços (48) ficou na segunda colocação, seguida de Educação e Saúde Mercantil (47). Essas atividades se caracterizam por possuir profissionais autônomos, e a maior parte do valor da produção é constituída pela renda do trabalho (o valor da produção pode ser obtido pela soma das remunerações do fator trabalho, mais excedente operacional bruto e rendimento misto bruto mais o consumo intermediário).

No que diz respeito à indústria da construção civil (39), esta ficou na décima primeira colocação geral. Para cada R\$ 1 milhão de reais gastos na demanda final, ela gera uma renda de R\$295.600 mil, sendo que R\$161.735 mil referem-se ao efeito direto, $\mathrm{R} \$ 55.949$ mil são do efeito indireto e R\$ 477.917 mil do efeito renda. Assim, para cada real gasto na construção civil, tem-se um incremento na renda de $\mathrm{R} \$ 0,83$.
Os resultados da pesquisa sobre o número total de empregos gerados ${ }^{2}$ na construção civil no estado do Paraná, em 2006, estão na Figura 2. Os empregos diretos totalizaram 305,84 mil, o que corresponde a $5,45 \%$ do pessoal ocupado na economia paranaense. Constata-se, ainda, que o efeito induzido gerou $77,42 \%$ de empregos a mais quando comparado com os empregos indiretos. Assim, têm-se 75,25 mil empregos gerados pelo crescimento da renda na economia - resultado do aumento da demanda final da atividade construção civil. O total de empregos foi de 423,5 mil, gerado pelo macrossetor da Construção Civil em 2006.

Nesta pesquisa, adotou-se o valor das remunerações do trabalho obtido na matriz de insumo-produto do Paraná em 2006. A Figura 3 apresenta o valor da renda gerada pelo fator trabalho da atividade construção civil, que totalizou R\$ 1.323 milhões em 2006, considerando as rendas direta, indireta e induzida. Observa-se que, neste caso, a renda induzida é superior à renda indireta. Foram gerados R\$ 180 milhões de renda induzida pelas demais atividades da economia. Assim, temos o total da renda gerado no valor de R\$ 2.418 milhões, o que equivale a dizer que cada real pago em salários gera $\mathrm{R} \$ 1,83$ na economia.

\section{Considerações finais}

Para mensurar o produto interno bruto, o emprego e a renda do macrossetor da Construção Civil, construiu-se uma matriz de insumo-produto utilizando-se o método do RAS, com o objetivo de elaborar a Tabela de Recursos e Usos paranaense, a preço de mercado. Adotou-se a prerrogativa de que o PIB, calculado com os dados da Tabela de Recursos e Usos, deve ser igual ao das contas regionais divulgado pelo IBGE. A partir disso, obteve-se a participação de $8,07 \%$ do macrossetor da Construção Civil na economia paranaense em 2006.

Quanto à questão dos multiplicadores de emprego e renda, foram utilizados dados da matriz de insumo-produto para a obtenção do número de pessoas ocupadas e renda no Paraná por atividade. Por meio da matriz calcularam-se os multiplicadores de emprego e renda.

\footnotetext{
${ }^{2}$ Para calcular o número total de empregos nas atividades econômicas, utilizou-se a Pesquisa Nacional de Amostra Domiciliar (PNAD) do IBGE (2007). O total dos empregos na PNAD é dividido em: empregado com carteira, empregado sem carteira, funcionário público, conta própria e empregador. Este trabalho utilizou o número total de trabalhadores da construção civil, que inclui os trabalhadores informais (empregado sem carteira e conta própria), o que corresponde a aproximadamente $45,36 \%$ dos trabalhadores em 2006.
} 


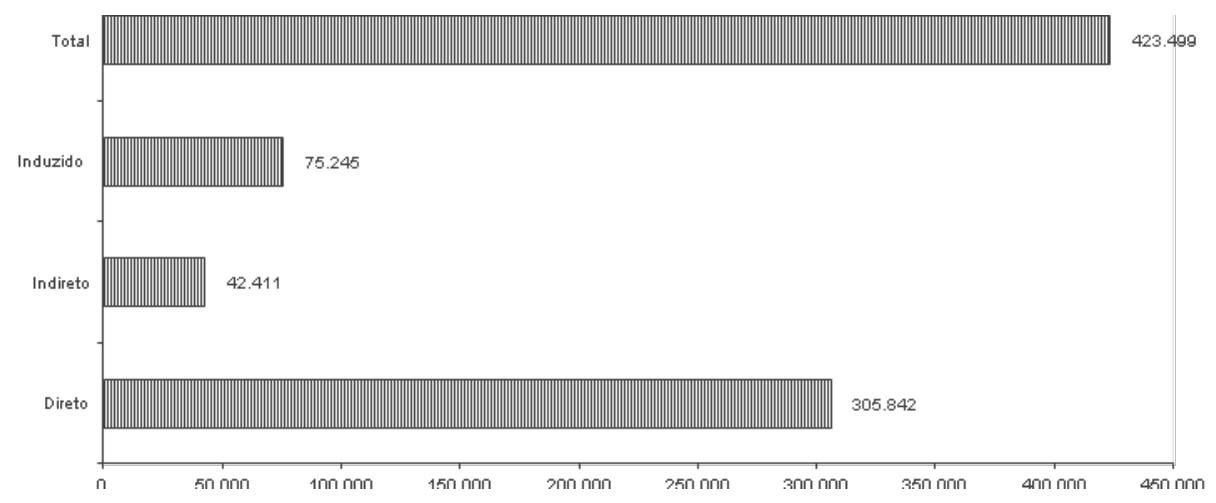

Figura 2 - Números de empregos diretos, indiretos, induzidos e totais gerados pelos gastos na construção civil no estado do Paraná em 2006

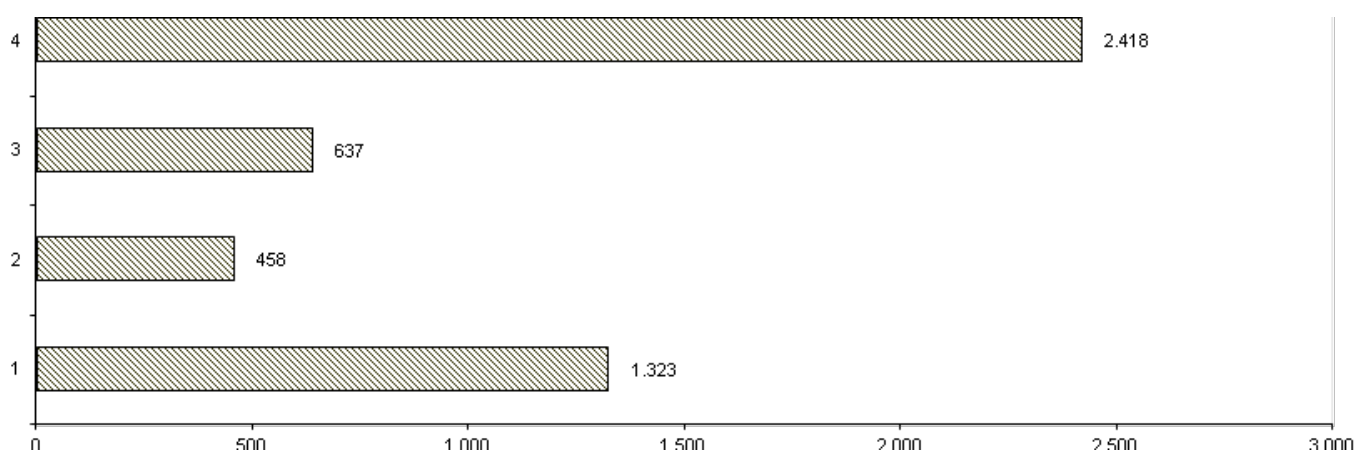

Figura 3 - Rendas diretas, indiretas, induzidas e totais geradas pelos gastos na construção civil no estado do Paraná, 2006

Nota: valores em milhões de reais.

A indústria da construção civil foi classificada na décima primeira colocação para os multiplicadores de emprego entre as 49 atividades, gerando 423,5 mil empregos, considerando os empregos direto, indireto e induzido. Finalizando, ficou na décima primeira colocação no multiplicador de renda. Por meio dos dados da demanda final de 2006, estimou-se que a construção civil gerou 2.418 milhões de reais como renda do trabalho.

Como sugestão, a pesquisa aponta a necessidade de realização de novos estudos para estimar o crescimento real do PIB no macrossetor da Construção Civil ou de outras atividades, como o agronegócio paranaense. Essa informação possibilitaria o acompanhamento do desempenho das principais atividades do estado, possibilitando a realização de políticas públicas e privadas específicas para determinadas atividades. Contudo, para estimar o crescimento real do PIB do macrossetor da Construção Civil é necessária a elaboração de matrizes de insumo-produto todos os anos. A elaboração de matriz de insumo-produto para outros estados possibilitaria a criação de matrizes interregionais, viabilizando estudos mais detalhados das relações econômicas entre os estados.

\section{Referências bibliográficas}

BRASIL. Ministério do Desenvolvimento, Indústria e Comércio Exterior. Secretaria de ComércioExterior. Aliceweb. Disponível em: $<$ http://aliceweb.desenvolvimento.gov.br/defau 1t.asp>.Acesso em: $28 \mathrm{dez} .2009$. 
CÂMARA BRASILEIRA DA INDÚSTRIA DA CONSTRUÇÃO CIVIL; FUNDAÇÃO Getúlio Vargas. Sumário Executivo. O Macrossetor da Construção. 2002. Disponível em:

$<$ http://www.cbicdados.com.br/files/textos/035.pdf >. Acesso em: 08 ago. 2011.

FINAMORE, E. B.; MONTOYA, M. A. PIB, tributos, emprego, salários e saldo comercial no agronegócio gaúcho. Ensaios FEE, Porto Alegre, v. 24, n. 1, p. 93-126, 2003.

FUNDAÇÃO DE ECONOMIA E ESTATÍSTICA SIEGFRIED EMANUEL HEUSER. Matriz de Insumo-Produto do Rio Grande do Sul: 2003. Porto Alegre: FEE, 2007. v. 1, 216 p.

GUILHOTO, J. J. M. et al. Nota Metodológica: construção da matriz insumo-produto utilizando dados preliminares das contas nacionais. In: ENCONTRO DE ESTUDOS REGIONAIS E URBANOS, 2., São Paulo, 2002. Anais... São Paulo, 2002. 1 CD-ROM.

GUILHOTO, J. J. M.; ICHIHARA, S. M.; POSTALI, F. A. S. The Importance of the Oil and Gas Complex for the Brazilian Economy and its States. In: CONGRESS OF THE EUROPEAN REGIONAL SCIENCE ASSOCIATION, 46., 2006, Volos. Proceedings... Volos: ERSA, 2006.

GUILHOTO, J. J. M.; FURTUOSO, M. C. O.; BARROS, G. S. de C. O Agronegócio na Economia Brasileira: 1994-1999. Piracicaba: CNA, 2000.

INSTITUTO Brasileiro de Geografia e Estatística. Classificação Nacional de Atividade Econômica - CNAE: versão 1.0. Rio de Janeiro: IBGE, 2003.

INSTITUTO Brasileiro de Geografia e Estatística. Pesquisa Nacional por Amostra de Domicílios: síntese de indicadores 2006. Rio de Janeiro: IBGE, 2007.
INSTITUTO BRASILEIRO DE GEOGRAFIA E ESTATÍSTICA. Sistema de Contas Nacionais Brasil 2002-2006. Rio de Janeiro: IBGE, 2008a. INSTITUTO BRASILEIRO DE GEOGRAFIA E ESTATÍSTICA. Pesquisa Industrial Anual 2006. Rio de Janeiro: IBGE, 2008b.

KURESKI, R.; CABALLERO, B. Método de Obtenção da Matriz de Insumo-Produto do Paraná para o Ano de 2000. Economia Aplicada, São Paulo, v. 9, n. 1, p. 121-137, jan./mar. 2005.

KURESKI, R. et al. O Macrossetor da Construção Civil na Economia Brasileira em 2004. Ambiente Construído, Porto Alegre, v. 8, n. 1, p. 7-19, jan./mar. 2008.

LOURENÇO, G. M. A indústria Paranaense em 2006. Análise Conjuntural, Curitiba, v. 29, n. 1/2, p. 17, jan./fev. 2007.

MIERNYK, W. H. Elementos de análise do insumo produto. São Paulo: Atlas, 1974. 164 p.

MILLER, R. Regional and interregional input-output analysis. In: AZIZ, I. et al. Methods of interregional and regional analysis. Aldershot, England: Ashgate, 1998.

OLIVEIRA E SILVA, A. B. de Metodologia da Matriz do Macrossetor da Construção para Minas Gerais. Belo Horizonte: CIC/Fiemg, 2006.

RICHARDSON, H. W. Insumo-Produto e Economia Regional. Rio de Janeiro: Zahar Editores, 1978.

WORLD BANK. The Construction Industry: issues and strategies in developing countries. Washington, DC: The World Bank, 1984.

\author{
Revista Ambiente Construído \\ Associação Nacional de Tecnologia do Ambiente Construído \\ Av. Osvaldo Aranha, $99-3^{\circ}$ andar, Centro \\ Porto Alegre - RS - Brasil \\ CEP 90035-190 \\ Telefone: +55 (51) 3308-4084 \\ Fax: +55 (51) 3308-4054 \\ www.seer.ufrgs.br/ambienteconstruido \\ E-mail: ambienteconstruido@ufrgs.br
}

142 Kureski, R. 